\title{
Why Should Medical Students be Concerned About Global Governance?
}

\author{
Renzo Guinto $\mathrm{MD}^{1}$ \\ ${ }^{1}$ Member, Lancet-University of Oslo Youth Commission on Global Governance for Health \\ Correspondence email: renzo.guinto@gmail.com
}

\begin{abstract}
This article introduces the work of the Lancet-University of Oslo Commission on Global Governance for Health and its parallel Youth Commission, which published their reports in 2014. Because the role of socioeconomic conditions in the production of health outcomes and health inequities has already long been recognized, the Commission further examined the "political determinants of health," particularly the systemic dysfunctions of global governance, especially in areas that are deemed as "non-health" such as trade, finance, agriculture, migration, and security. To support the Commission's thesis, the Youth Commission then proposed the adoption of the "capability approach" as a guiding framework of global governance for health. First introduced by Amartya Sen, this approach emphasizes on the need for equality in the space of capabilities or freedoms needed to achieve various things that people value. Nevertheless, while the road toward better global governance remains elusive, the next generation of leaders, including medical students, can already be prepared to tackle these seemingly insurmountable challenges. Various ways by which medical students can learn and understand global governance and global health include incorporation into the medical curriculum, internships, and involvement in student organizations with global health orientation. Such modalities are hoped to contribute towards the full reorientation of the health professions to consider, address, and reach out to other sectors that govern the broader, underlying social determinants of health
\end{abstract}

\footnotetext{
Copyright Royal Medical Society. All rights reserved. The copyright is retained by the author and the Royal Medical Society, except where explicitly otherwise stated. Scans have been produced by the Digital Imaging Unit at Edinburgh University Library. Res Medica is supported by the University of Edinburgh's Journal Hosting Service: http://journals.ed.ac.uk

ISSN: 2051-7580 (Online) ISBN: 0482-3206 (Print)

Res Medica is published by the Royal Medical Society, 5/5 Bristo Square, Edinburgh, EH8 9AL 


\section{Why Should Medical Students be Concerned About Global Governance?}

On February 11 2014, the Lancet-University of Oslo Commission on Global Governance for Health (Commission hereafter) released its report on the "political origins of health inequity". The Commission, composed of eminent leaders from various disciplines, examined the interplay between health and other sectors traditionally deemed as "nonhealth" such as trade, finance, agriculture, migration, and security and how policies and outcomes in these areas produce inequities in health - "differences which are unnecessary and avoidable but, in addition, are also considered unfair and unjust". ${ }^{2}$ The Commission's report can be seen as a sequel to the WHO Commission on Social Determinants of Health, which in 2008 concluded that health inequalities are rooted in the conditions in which people are born, grow, live, work and age. ${ }^{3}$

However, the recognition of the social production of health and health inequalities is not a novel idea. As early as the $19^{\text {th }}$ century, the German physician Rudolf Virchow, known as the "Father of Social Medicine," asked: "Do we not always find the diseases of the populace traceable to defects in society?"4 Clearly, the question remains valid until today, especially now that health is becoming inextricably interlinked with not just domestic but also, and perhaps more importantly, global drivers. The global epidemic of noncommunicable diseases, particularly heart disease, diabetes, and obesity, which disproportionately affects the world's poor, is hugely a result of the globalization of risk factors such as unhealthy diets and tobacco, which in turn is made possible by unrestricted and unfair trade regimes. ${ }^{5}$

Nevertheless, while the WHO Commission reviewed scientific evidence establishing the links between social determinants and health outcomes, the Commission adopted a governance lens in attempting to understand the ultimate causes of health inequities and the dynamics surrounding these relationships. It looked at case studies from various policy areas and identified systemic dysfunctions that impede what the Commission called "global governance for health," loosely yet broadly defined as "all governance areas that can affect health." Another term that the Commission introduced is "political determinants of health," which refers to "norms, policies, and practices that arise from transnational interaction" and thus is distinguished from "social determinants."

It was obvious to the Commission that power asymmetries among nation states as well as 
other actors, including intergovernmental institutions, translate into gross inequities in health between countries. Furthermore, such maldistribution of power and resources is reinforced by systemic global governance dysfunctions identified by the Commission such as: deficits in democratic participation of disadvantaged countries, institutions, and individuals; weak accountability among actors; and limited policy space for health in a global governance system that prioritizes "hard" issues such as trade and security. In response to these challenges, the Commission proposed the creation of additional international mechanisms, such as a Multistakeholder Platform on Governance for Health and an Independent Scientific Monitoring Panel, and called on the global community to make health "a universal value and a shared social and political objective for all."

The ideas of the Commission are generally supported by its parallel Youth Commission ${ }^{6}$, of which the author of this article is a member. The Youth Commission, however, advocated for the adoption of the "capability approach," which was first introduced by Nobel Prize-winning development economist Amartya Sen. ${ }^{7}$ This approach emphasizes a rethinking of human development not as equality of outcomes such as health, educational attainment, and income, but as equality in the space of capabilities - the real opportunity or, in Sen's language, "freedom," people have in order to pursue and achieve various things they value. The Youth Commission's report pointed out the need to broaden the discussion of "global governance for health" to global governance for the promotion of human capabilities or, as succinctly put in its title, to work toward "advancing health by enhancing capabilities". 8 The more concrete mechanisms that will drive this new agenda are still yet to be discussed and designed however.

Despite these analyses, it is clear that global governance cannot be changed overnight. For instance, it took nearly a century for the current global governance system to evolve its formal structure that is the United Nations system; the informal interactions between nation states and other actors; and the emerging hybrid institutional arrangements ranging from free trade agreements to regional blocs. Global governance can be seen as a product of historical processes, which may not be consciously conceived by its participants, but rather are the results of circumstances in the broader physical and social environment. But if global governance is to transform for it to work for health and not against it, then the bold and necessary steps have to be deliberately undertaken as 
early as now. These include preparing the next generation of leaders who will be in the forefront of tackling these seemingly insurmountable challenges of global governance in the near future.

Medical students are one important group of future leaders who need to be exposed early on to the realities of global governance and human development. They need to be targeted because physicians enjoy a unique and high stature in their respective societies, making them capable of influencing others. They are also often bestowed with decisionmaking roles and appointed in positions of power within the health sector and, at times, even beyond, whether in the community, national, or international levels.

By the time they become fully fledged physicians, today's medical students will be expected to confront complicated global health challenges whose causes cannot be traced to any single cause or determinant. New international institutional arrangements would have already been established, as a result of both the post-2015 development agenda that is currently being negotiated within the auspices of the United Nations ${ }^{9}$ and the global transitions that are foreseen today to become full-blown in a few decades' time such as climate change, overpopulation, and the rise of new superpowers and emerging markets $^{10}$. These future health leaders will therefore have to be prepared for dealing with complexity and leading positive change at the same time.

So how do we go about it - the education and early exposure of medical students to the global political determinants of health? Currently, momentum is building around transformative education of health professionals $^{11,12}$ with the hope that such a movement will support the broader health goal of universal health coverage. ${ }^{13}$ Furthermore, there are calls for reorientation of the entire health sector from a purely biomedical view toward a more holistic biopsychosocial perspective. For instance, a 2013 report of the Institute of Health Equity at the University College London identified advocacy as one of the fundamental roles of health professionals, urging "individual health professionals, students and professional bodies... [to] advocate for policy changes that would improve the social and economic conditions in which people live, and particularly those that would reduce inequalities in these conditions". ${ }^{14}$

The modalities by which the goal of preparing medical doctors for global leadership can be achieved may differ from one context to another. Nonetheless, several attempts have actually been made to develop a core 
curriculum for global health in medical education. ${ }^{15-17}$ Beyond the formal curriculum, internships in global health institutions such as the WHO are being encouraged by many academic institutions; however, such opportunities remain to be extended to students from low- and middle-income countries. ${ }^{18}$ Student organizations such as the International Federation of Medical Students' Associations (IFMSA) have also been providing extracurricular platforms for global health learning through its advocacy and education projects at local, regional, and global levels, as well as by exposing student leaders to global governance structures such as the World Health Assembly ${ }^{19}$ and the annual conferences of the United Nations Framework Convention on Climate Change. ${ }^{20}$

Health has become more complex than ever before, and so the next generation of doctors must be ready to face these present realities which have long-term consequences on health and well-being of populations in the future. Clearly, just within the health sector alone, much needs to be done to put the house in order first. Reorientating the health professions is a critical first step so that the health sector can then reach out to other sectors that govern the broader, underlying social determinants of health. Education and training have a role to play in this paradigm shift, and there is enough space for innovation from education institutions and non-formal organizations alike as they shape tomorrow's global health leaders today.

Trained as a physician in the Philippines, Renzo $\boldsymbol{R}$. Guinto, $\boldsymbol{M D}$ is a Member of the Lancet-University of Oslo Youth Commission on Global Governance for Health, Consultant of the International Organization for Migration and Philippine Department of Health, Member of the Universal Health Care Study Group of the University of the Philippines, Moderator of the Social Determinants of Health section of the WHO Transformative Education of Health Professions website, former Liaison Officer to the World Health Organization of the International Federation of Medical Students' Associations (IFMSA), and International Liaison Editor of Res Medica. 


\section{Learning points}

\section{What is already known?}

- Inequities in health, which are unnecessary, avoidable, and unfair differences in health access and outcomes, are rooted in the social, economic, and political conditions in which people live in.

- Health outcomes, such as the global epidemic of non-communicable diseases, are hugely shaped by the globalization of risk factors through processes such as unrestrained and unfair trade.

- The maldistribution of power and resources globally, as well as systemic dysfunctions in the global governance system such limited democratic participation in decisionmaking, weak accountability, and limited policy space for health, contribute to the production of global health inequities.

\section{What does this article add?}

- First introduced by Amartya Sen, the "capability approach," which emphasizes on the need for equality in the space of capabilities or freedoms needed to achieve various things that people value, may provide a common framework for better global governance for health.

- In order to prepare a new generation of health leaders that can address today's complex health challenges, global governance and global health must be incorporated in the education and training of medical students.

- There are diverse ways to educate medical students on the global governance for health - through incorporation in the curriculum, internships, and involvement in student organizations such as the International Federation of Medical Students' Associations (IFMSA). 


\section{References}

1. Ottersen OP, Dasgupta J, Blouin C, et al. The political origins of health inequity: prospects for change. Lancet 2014. published online Feb 11. http://dx.doi.org/10.1016/S0140-6736(13)62407-1.

2. Whitehead M. The concepts and principles of equity in health. Int J Health Serv 1992;22:429-445.

3. Commission on Social Determinants of Health. Closing the gap in a generation: health equity through action on the social determinants of health. Final report of the Commission on Social Determinants of Health. Geneva: World Health Organization, 2008.

4. Virchow R. Collected essays on public health and epidemiology. Cambridge: Science History Publications, 1848/1985.

5. Beaglehole R, Yach D. Globalisation and the prevention and control of non-communicable disease: the neglected chronic diseases of adults. Lancet 2003; 362: 903-08.

6. Gopinathan U, Danielsen L, Lie AL. Why a Youth Commission on Global Governance for Health?. Lancet 2012; 380: 338-339.

7. Sen A. Development as freedom. New York: Oxford University Press, 1999.

8. Gopinathan U, Watts N, Cuadrado C, Hougendobler D, Meganathan S, Lefebvre A, et al. Advancing health by enhancing capabilities: an agenda for equitable global governance. 2014 (accessed 29 July 2014). Available from: http://www.uio.no/global-governance-health/publications/youth-commission.html.

9. WHO, UNICEF, Government of Sweden, Government of Botswana. Health in the post-2015 agenda. Report of the global thematic consultation on health. 2014 (accessed 28 July 2014). Available from: http://www.worldwewant2015.org/file/337378/download/366802.

10. Frenk J, Moon S. Governance Challenges in Global Health. N Engl J Med 2013; 368:936-942

11. Frenk J, Chen L, Bhutta ZA, Cohen J, Crisp N, Evans T, et al. Health professionals for a new century: transforming education to strengthen health systems in an interdependent world. Lancet 2010; 376: 1923-1958.

12. World Health Organization. Transforming and scaling up health professionals' education and training: WHO Education Guidelines 2013. Geneva: WHO, 2014.

13. World Health Assembly. Resolution 66.23. Transforming health workforce education in support of universal health coverage. Geneva: World Health Organization, 2013.

14. University College London (UCL) Institute of Health Equity. Working for health equity: the role of health professionals. London: UCL, 2013.

15. Bozorgmehr K, Saint V, Tinnemann P. The 'global health' education framework: a conceptual guide for monitoring, evaluation and practice. Global Health. 2011; 7: 8. doi: 10.1186/1744-8603-7-8

16. Rowson M, Willott C, Hughes R, Maini A, Martin S, Miranda JJ, et al. Conceptualising global health: theoretical issues and their relevance for teaching. Global Health. 2012 Nov 14;8:36. doi: 10.1186/1744-8603-8-36.

17. Yudkin JS, Bayley O, Elnour S, Willott C, Miranda JJ. Introducing medical students to global health issues: a Bachelor of Science degree in international health. Lancet 2003, 362:822-824.

18. Barnett-Vanes A, Kedia T, Anyangwe S. Equitable access for global health internships: insights and strategies at WHO headquarters. The Lancet Global Health, Volume 2, Issue 5, Pages e257 - e259, 2014 May. doi:10.1016/S2214-109X(14)70211-6

19. Pleyer C, Dhatt R, Guinto R, Thompson K, Mares de Leon A, Iverson JH, et al. The role of young people in global health governance: an interview-based observational study. The Lancet, Volume 382, Page 12, 2013 October 20. doi:10.1016/S0140-6736(13)62173-X

20. Desrosiers C, Holm-Hansen C, Tcholakov Y, Watts N. Climate and Health - a call for action from tomorrow's global leaders [Internet]. [Place unknown]: Translational Global Health, 2013 November 16 [cited 2014 July 28]. Available from: http://blogs.plos.org/globalhealth/2013/11/ifmsa-cop/. 